\title{
NOTA
}

\section{INCREMENTO DA EXATIDÃO DA ANÁLISE GRANULOMÉTRICA DO SOLO POR MEIO DA COLETA DA SUSPENSÃO (SILTE + ARGILA) $)^{(1)}$}

\author{
Hugo Alberto Ruiz (2)
}

\begin{abstract}
RESUMO
A análise granulométrica do solo é realizada em três etapas: aplicação de pré-tratamentos para remoção de agentes cimentantes e floculantes, dispersão da amostra de solo e quantificação das frações do solo. Para quantificar as frações do solo, há necessidade de separá-las previamente. Dependendo do tamanho, utiliza-se o peneiramento, para as frações areia grossa e areia fina, ea sedimentação, para as frações silte e argila. Algumas propostas metodológicas calculam a proporção da fração silte no sistema por subtração das outras frações em relação à amostra origi nal. No Laboratório de Física do Solo da Universi dade Federal de Viçosa, realiza-se a coleta adicional da suspensão (fração silte + fração argila), o que incrementa a exatidão do resultado. As determinações que não levam em consideração esta coleta superestimam a proporção da fração silte, acumulando nesta fração a totalidade dos erros da determinação. Pode-se concluir que a coleta da suspensão (fração si lte + fração argila) e a seqüência de cálculos decorrentes desta coleta levam a resultados mais adequados na análise granulométrica do solo, distribuindo o erro experimental nas quatro frações granulométricas.
\end{abstract}

Termos de indexação: análise textural, frações do solo, análise mecânica, método da pipeta.

\section{SUMMARY: INCREASED ACCURACY IN PARTICLE-SIZE ANALYSIS BY SAMPLING THE SILT + CLAY SUSPENSION}

Three main stages are involved in particlesize analysis: pretreatment of samples to removecementing and flocculating agents, sampledispersion and soil fraction quantification. This quantification requires the previous separation of the soil fractions. According to the size, coarseand finesand fractions areseparated by si eving, whil esilt and clay areseparated

(1) Recebi do para publicação em julho de 2003 e aprovado em dezembro de 2004.

(2) Professor do Departamento de Solos, Universidade Federal de Viçosa - UFV. CEP 36571-000 Viçosa (MG). Bolsista do CNPq. E-mail: hruiz@ufv.br 
by sedimentation. Some methods propose to calculate the silt proportion by subtracting the other soil separates from the original sample. In the Soil Physics Laboratory at the Federal U niversity of Viçosa, Brazil, an additional suspension (silt + dlay) is coll lected to increasetheaccuracy in theparticlesizeanalysis. Methods that do not take this aspect into account overestimate the silt proportion by accumulating all experimental errors in this fraction. It can beconcluded that the silt + clay determination and resulting calculations lead to better results in thesoil particlesize analysis as they distribute the experimental error among the four granul ometric fractions.

Index terms: soil separates, soil fraction, mechanical analysis, pipet method.

A análise granulométrica do solo é realizada em três etapas: aplicação de pré-tratamentos para remoção de agentes cimentantes e floculantes, dispersão da amostra de solo e quantificação das frações do solo. A primeira etapa, normalmente pouco utilizada nas análises de rotina, visa à remoção de matéria orgânica, óxidos de $\mathrm{Fe}$, carbonatos e sais solúveis (Gee \& Bauder, 1986). Considerando, especificamente, os óxidos de $\mathrm{Fe}$, o tratamento com solução de ditionito-citratobicarbonato, proposto por Mehra \& J ackson (1960), não deveria ser utilizado em solos das regiões tropicais e úmidas. Esse pré-tratamento pode dissolver partículas deóxidos deFe dotamanho das argilas, influenciando os resultados da análise textural. Para esses solos, indicam-se prétratamentos menos drásticos, como o que utiliza solução de ácido clorídrico a 0,05 mol L-1 (Barreto, 1986).

A dispersão da amostra de solo é fundamental na análise granulométrica. Esta etapa é realizada mediante o uso de uma combinação de processos químicos e desagregação mecânica. A dispersão química é baseada, fundamentalmente, no incremento da repulsão das partículas em resposta à el evação do seu potencial zeta. Este processo é normal mente realizado pela saturação do complexo de troca catiônico com $\mathrm{Na}$, pelo incremento das cargas negativas em resposta ao aumento do $\mathrm{pH}$ e pela diminuição da concentração de eletrólitos na solução, provocando a preci pitação de compostos de Al ou Ca, segundo o cátion predominante no complexo detroca - esta última característica leva à escolha do dispersante químico a ser utilizado: hidróxido de $\mathrm{Na}$ ou hexametafosfato de $\mathrm{Na}$, respectivamente. A dispersão mecânica pode ser realizada por agitação rápida, agitação lenta ou ultra-som (Gee \& Bauder, 1986).

Para quantificar as frações do solo, há necessidade desepará-las previamente. Dependendo do tamanho, utiliza-se o peneiramento, para as frações areia grossa e areia fina, ea sedimentação, para as frações silteeargila. Em setratando da estimativa dotempo de sedimentação da fração silte, restringindo a porção superior da suspensão às partículas de argila, utiliza-se a Lei de Stokes, com algumas aproximações, que permitem sua utilização para o caso específico das partículas de solo (K honke, 1969). A separação por peneiramento leva a resultados de maior confiabilidade, porém a separação por sedimentação seimpõe na diferenciação das frações silte e argila, por não haver peneiras de 0,002 mm.

O Manual de Métodos de Análise deSolo, editado pela E mbrapa, compila métodos de análises físicas, químicas e mineralógicas. As duas edições dessa obra (E mbrapa, 1979, 1997) são assiduamente consultadas, e os métodos, amplamente utilizados na caracterização dos solos. Na descrição da análise granulométrica pelo método da pipeta, após a separação das areias por peneiramento, o roteiro indica agitar a suspensão (fração silte + fração argila), determinar a temperatura da suspensão para estabelecer o tempo de sedimentação e, após esse período, realizar a coleta da suspensão da fração argila. Assim, a proporção da fração silte no sistema é calculada por subtração das outras frações em relação à amostra original.

No Laboratório de Física do Solo do Departamento de Sol os da Universidade F ederal de Viçosa (LFS/UFV), trabalhando com proporções de solo, do dispersante e do volume de suspensão similares às da Embrapa (1997), realiza-se uma coleta adicional da suspensão (fração silte + fração argila), o que incrementa a exatidão da determinação. I sso será mostrado por meio das equações utilizadas nos cál culos.

Adequando as equações apresentadas por Embrapa (1997) para expressar as proporções das frações em kg kg-1, os teores $\left(X_{i}\right)$ de areia fina (AF), areia grossa $(A G)$, argila $(A r g)$ e silte $(S)$ são calculados da seguinte forma:

$$
\begin{gathered}
\mathrm{x}_{\mathrm{AF}}=\mathrm{M}_{\mathrm{AF}} \frac{1}{\mathrm{M}_{\mathrm{TFSA}}} \\
\mathrm{x}_{\mathrm{AG}}=\left[\mathrm{M}(\mathrm{AF}+\mathrm{AG})-\mathrm{M}_{\mathrm{AF}}\right] \frac{1}{\mathrm{M}_{\mathrm{TFSA}}}
\end{gathered}
$$




$$
\begin{aligned}
& \mathrm{x}_{\mathrm{Arg}}=\left[\mathrm{M}(\operatorname{Arg}+\mathrm{D})-\mathrm{M}_{\mathrm{D}}\right] \frac{\mathrm{V}_{\mathrm{T}}}{\mathrm{V}_{\mathrm{C}}} \frac{1}{\mathrm{M}_{\text {TFSA }}} \\
& \mathrm{x}_{\mathrm{S}}=1-\left(\mathrm{x}_{\mathrm{AG}}+\mathrm{x}_{\mathrm{AF}}+\mathrm{x}_{\mathrm{Arg}}\right)
\end{aligned}
$$

em que M éa massa $(\mathrm{g})$ das frações do solo, da terra fina seca ao ar (TFSA) e do dispersante (D); $\mathrm{V}_{\mathrm{T}}$, o volume total da dispersão $(\mathrm{mL})$, e $\mathrm{V}_{\mathrm{C}}$, o volume col etado $(\mathrm{mL})$.

As proporções cal culadas com as equações de 1 a 4 não levam em consideração a umidade residual da TFSA. Na realidade, os resultados obtidos deveriam ser multiplicados por um fator $f$ de modo a referi-los à terra fina seca em estufa (TFSE) (Vettori, 1969):

$$
\mathrm{f}=\frac{\mathrm{M}_{\mathrm{TFSA}}}{\mathrm{M}_{\mathrm{TFSE}}}
$$

A primeira edição do manual da Embrapa (1979) incluía o fator $f$ no cálculo das frações areia fina, areia grossa e argila, diminuindo o erro introduzido no cál culo da fração silte. As equações 1, 2 e 3 eram apresentadas assim:

$$
\begin{gathered}
x_{A F}=M_{A F} \frac{1}{M_{T F S A}} f \\
x_{A G}=\left[M(A F+A G)-M_{A F}\right] \frac{1}{M_{T F S A}} f \\
x_{A r g}=\left[M(A r g+D)-M_{D}\right] \frac{V_{T}}{V_{C}} \frac{1}{M_{T F S A}} f
\end{gathered}
$$

e a fração silte calculada conforme a equação 4.

No LFS/UFV, a coleta da fração (silte + argila) leva à determinação de uma massa adicional $\left[\mathrm{M}_{(\mathrm{S}+\mathrm{Arg})}\right]$. Por outrolado, as massas das frações areia grossa eareia fina são determi nadas separadamente. Assim, a fração areia fina é cal culada pela equação 6 , a fração argila, pela equação 8 , e as frações restantes, pelas equações:

$$
\begin{gathered}
\mathrm{x}_{\mathrm{AG}}=\mathrm{M}_{\mathrm{AG}} \frac{1}{\mathrm{M}_{\mathrm{TFSA}}} \mathrm{f} \\
\mathrm{x}(\mathrm{S}+\mathrm{Arg})=\left[\mathrm{M}(\mathrm{S}+\mathrm{Arg}+\mathrm{D})-\mathrm{M}_{\mathrm{D}}\right] \frac{\mathrm{V}_{\mathrm{T}}}{\mathrm{V}_{\mathrm{C}}} \frac{1}{\mathrm{M}_{\mathrm{TFSA}}} \mathrm{f} \\
\mathrm{x}_{\mathrm{S}}=\mathrm{x}(\mathrm{S}+\text { Arg })-\mathrm{x}_{\mathrm{Arg}}
\end{gathered}
$$

O somatório das proporções de todos os componentes de um sistema deve ser, necessariamente, igual à unidade $\left(\Sigma x_{i}=1\right)$. No entanto, normalmen- te, oval or exato nãoéalcançado. Assim, recalculamse as proporções de forma a atingir o val or unitário, utilizando as expressões:

$$
\begin{gathered}
x_{A G}^{\prime}=\frac{x_{A G}}{\Sigma x_{i}} \\
x_{A F}^{\prime}=\frac{x_{A F}}{\Sigma x_{i}} \\
x_{S}^{\prime}=\frac{x_{S}}{\Sigma x_{i}} \\
x^{\prime}{ }_{A r g}=\frac{x_{A r g}}{\Sigma x_{i}}
\end{gathered}
$$

Nas determinações realizadas no LFS/UFV, pesam-se aproximadamente $10 \mathrm{~g}$ de TFSA, com aproximação de 0,01 g. Acrescentam-se $50 \mathrm{~mL}$ de solução de $\mathrm{NaOH}$ 0,1 mol L-1 e $150 \mathrm{~mL}$ de água deionizada, agitando com bastão de vidro e deixando em repouso por uma noite. A amostra é dispersada por agitação a 12.000 rpm, durante 15 min. Após passar a suspensão por peneira de 0,053 mm, aferese a mistura das frações silte e argila até $500 \mathrm{~mL}$, coletando-se $25 \mathrm{~mL}$ da suspensão (fração silte + fração argila) imediatamente após agitação com bastão de vidro. Decorrido o tempo calculado pela Lei de Stokes para a temperatura de trabalho, coletam-se, dos $5 \mathrm{~cm}$ superficiais, $25 \mathrm{~mL}$ da suspensão de argilas. Por peneiramento através de malha de 0,210 mm, separam-se a areia grossa e a areia fina. Todas as frações são secas em estufa a $100{ }^{\circ} \mathrm{C}$ e pesadas com aproximação de $0,01 \mathrm{~g}$, para areia grossa e areia fina, e de 0,0001 g, para as frações (silte + argila) e argila. Como exemplo, a partir dos dados da análise granulométrica, foram calculadas as proporções das frações areia grossa, areia fina, silte e argila, utilizando as equações apresentadas por E mbrapa $(1979,1997)$ e por este trabalho (Quadro 1).

Como se observa (Quadro 1), os cálculos indicados por Embrapa (1979) superestimam a proporção da fração silte, que acumula a totalidade dos erros da determinação. Esse valor é ainda maior no método descrito por E mbrapa (1997), por se omitir o uso do fator $f$, que permite a correção das determinações para terra fina seca em estufa. Assim, pode-se concluir que a coleta da suspensão (fração silte + fração argila) ea seqüência de cál culos apresentados neste trabal ho levam a resultados mais adequados da análise granulométrica, diminuindo também os valores da relação silte/argila, utilizados como critério na caracterização e classificação de solos. 


\section{Quadro 1. Frações texturais de um Latossolo calculadas por E mbrapa $(1979,1997)$ e pelo método proposto neste trabalho, a partir de dados de análise realizada no LFS/UFV}

\begin{tabular}{|c|c|c|c|}
\hline F ração do solo & E mbrapa (1979) & E mbrapa (1997) & Método proposto \\
\hline & \multicolumn{3}{|c|}{ - $\mathrm{kg} \mathrm{kg}^{-1}$} \\
\hline Areia grossa & 0,197 & 0,191 & 0,209 \\
\hline Areia fina & 0,102 & 0,099 & 0,109 \\
\hline Silte & 0,124 & 0,151 & 0,070 \\
\hline Argila & 0,577 & 0,559 & 0,612 \\
\hline \multicolumn{4}{|c|}{ Dados utilizados nos cálculos: } \\
\hline & $\begin{array}{r}\text { Massa de terra fir } \\
\text { Massa de terra fina se } \\
\text { Massa de } \\
\text { Massa } \\
\text { Massa de silte + argila } \\
\text { Massa de argila } \\
\text { Massa do } \\
\text { Volume } \\
\text { Vol }\end{array}$ & $\begin{array}{l}\text { o ar }=10,38 \mathrm{~g} \\
\text { tufa }=10,06 \mathrm{~g} \\
\text { ossa }=1,98 \mathrm{~g} \\
\text { fina }=1,03 \mathrm{~g} \\
\text { ante }=0,3335 \mathrm{~g} \\
\text { ante }=0,3003 \mathrm{~g} \\
\text { ante }=0,0100 \mathrm{~g} \\
\text { tsão }=500 \mathrm{~mL} \\
\text { tado }=25 \mathrm{~mL} \\
\text { tor } \mathrm{f}=1,032 \mathrm{~kg}\end{array}$ & \\
\hline
\end{tabular}

\section{LITE RATURA CITADA}

BARRETO, W. Eletroquímica de solos tropicais de carga variável: capacidade da dupla camada elétrica. Itaguaí, Universidade Federal Rural do Rio deJ aneiro, 1986. 273p. (Tese de Doutorado)

EMPRESA BRASILEIRA DE PESQUISA AGROPECUÁRIA EMBRAPA. Manual de métodos de análise de solo. Rio de J aneiro, Serviço Nacional de Levantamento e Conservação de Solos, 1979. 247p.

EMPRESA BRASILEIRA DE PESQUISA AGROPECUÁRIA EMBRAPA. Manual de métodos de análise de solo. 2.ed. Rio deJ aneiro, Centro Nacional de Pesquisa de Solos, 1997. 212p.
GEE, G.W. \& BAUDER, J .W. Particle-sizeanalysis. In: KLUTE, A., ed. Methods of soil analysis. Part 1. Physical and mineralogical methods. 2.ed. Madison, American Society of Agronomy, Soil Science Society of America, 1986. p.383411. (Agronomy Series, 9)

KHONKE, H. Soil physics. 2.ed. New York, MacGraw Hill, 1969. $224 p$.

MEHRA, O.P. \& J ACKSON, M.L. I ron oxide removal from soils and clays by dithionite-citrate system buffered with sodium bicarbonate. In: NATIONAL CONFERENCE ON CLAYS AND CLAY MINERALS, 7., Washington, DC, 1958. Proceedings. New York, Pergamon Press, 1960. p.317-327.

VETTORI, L. Métodos de análise de solo. Rio de J aneiro, Ministério da Agricultura, Equipe de Pedologia e Fertilidade do Solo, 1969. 24p. (Boletim Técnico, 7) 